\title{
THE PROCESS OF MIGRATION AND THE REINVENTION OF SELF: THE EXPERIENCES OF RETURNING IRISH EMIGRANTS
}

\author{
MARY P. CORCORAN
}

IRISH migration at the end of the twentieth century encompasses complex and multidimensional processes. Whereas Irish emigrants were once drawn almost exclusively from the agricultural and laborer classes, in the closing decades of the twentieth century emigration came to permeate the entire social system. Thus, Irish migrants are to be found not just among the ranks of skilled and semi-skilled labor, but also among the transnational professional élite that crisscrosses the globe. Current migration trends suggest a radical departure from the pattern that has characterized Irish demography for more than two centuries. Nowadays, more people are entering Ireland than leaving, bringing the country's migratory profile more into line with its European partners. Indeed, Irish government agencies are currently engaged in campaigns to recruit non-national immigrants in key labor market niches and to attract Irish emigrants home. Furthermore, there has been a significant increase in the numbers of nonnationals seeking asylum in Ireland over the last ten years. The study of migration and its meaning in the context of the unprecedented buoyancy of the Irish economy directs us to new concerns about multiculturalism, immigration policy and practices, Ireland's position in the global economy, and the relationship between the Irish diaspora and the homeland.

This article is based on a set of qualitative interviews involving a crosssection of emigrants who left Ireland in the 1980 s and returned in the 1990s. Particular attention is paid to their motivations for leaving and their experiences abroad in terms of professional and personal development. Analysis of the data reveals that these returners have been able to exercise considerable autonomy in terms of making decisions about their careers, and that in many instances they have used their time abroad to reinvent themselves in terms of their professional career trajectory. Yet, 
they are drawn back to Ireland in a quest for "community" and better "quality of life," both of which have become more elusive in the fragmented and deeply individualized society that underpins the "Celtic Tiger."

\section{EMIGRATION TRENDS AND RETURN MIGRATION}

In the sixty years after the foundation of the Irish State, Ireland on average lost 0.5 percent of its population annually through net emigration. In the 1950s, the emigration rate rose to I.5 percent of the population, a rate of outflow that was previously surpassed only in the 1840 os and I880s. ${ }^{1}$ The post-1958 opening up of the Irish economy to foreign investment brought a significant increase in the growth rate and a rise in living standards. Average annual net emigration fell from 43,000 per annum between 1956 and I96I to 16,000 between $196 \mathrm{I}$ and 1966, and to II,000 between 1966 and 1971. This corresponds to a drop from an annual gross emigration rate of I4. 8 percent to 3.7 percent of the population. ${ }^{2}$

Between $197 \mathrm{I}$ and 1979 , Ireland for the first time experienced net immigration, reversing a two-centuries old trend. Arrivals exceeded departures by about 109,000 people, mainly due to Irish emigrants returning from Britain to take advantage of opportunities in the resurgent economy. But, significantly, net emigration from Ireland persisted even in this period in the 15 to 24 age group and among men in the 25 to 34 age group. ${ }^{3}$ That suggests that many newly created jobs went to returned emigrants who brought with them skills and experience, while Ireland's youth continued to seek work abroad. The relative prosperity that marked the 1960 and 1970s in Ireland was short-lived and, by the mid-1980s, unemployment and emigration were both increasing. The annual average migratory outflow rose to nearly 34,000 between 1986 and $1990 .{ }^{4}$ As emigration began to rise inexorably in the 1980s, the focus of attention shifted away from returners and toward the burgeoning diasporic communities in the United States

I Brendan Walsh, "Emigration: An Economist's Perspective," Policy Paper PP88/3 (Dublin: University College Dublin Centre for Economic Research, 1988), 2.

2 J.J. Lee, Ireland I9I2-I985: Politics and Society (Cambridge, U.K.: Cambridge University Press, 1989), 359-60. Gross emigration is the total number or rate of departures; net emigration is gross emigration minus arrivals.

3 Paul Tansey, "Figures Hid Facts of Irish Exodus," Sunday Tribune, in November I989, B8.

4 Central Statistics Office Annual Population and Migration Estimates, rg8r-rggo (Dublin: Central Statistics Office, 1991). 
and elsewhere. Overall, then, Ireland's migratory profile up until the last decade of the twentieth century can be characterized as one of emigration rather than immigration, with the exception of the 1970s, when a pattern of return emigration was identified.

In the r99os, however, more people entered Ireland than left it, bringing the national migratory profile more into line with that of the European Union. Between 1991 and 1998 Ireland experienced an average inflow of some 37,000 immigrants each year. In 1998 arrivals exceeded departures by 22,800 , a historical high point. The combined effect of this flow and the excess of births over deaths in the same period resulted in a population figure of 3.7 million in April 1998, up I.2 percent on the previous April. More than half ( 53 percent) of all immigrants to Ireland in 1998 were Irish nationals, most of whom (43 percent) were concentrated in the 25 to 44 age category. ${ }^{5}$

TABLE I

ESTIMATED NET MIGRATION, 199I-98

\begin{tabular}{ll}
\hline 1991 & $-2,000$ \\
1992 & $+6,100$ \\
1993 & -400 \\
1994 & $-4,700$ \\
1995 & $-1,900$ \\
1996 & $+8,000$ \\
1997 & $+15,000$ \\
1998 & $+22,800$ \\
\hline
\end{tabular}

Source: Central Statistics Office

There is a dearth of literature on return migration to Ireland. Fiona McGrath suggests two reasons that this is the case: the fact that much of the nineteenth-century movement involved little return, and the statistical elusiveness of the return flow. ${ }^{6}$ Hence, our knowledge about returners remains extremely limited. Matthew $\mathrm{O}^{\prime} B r i e n$, using census data and labor force surveys among other sources, has identified a circulating migra-

5 Central Statistics Offece Annual Population and Migration Estimates, 199I-19g8 (Dublin: Central Statistics Office, 1999).

6 Fiona McGrath, "The Economic, Social and Cultural Impact of Return Migration to Achill Island," in R. King, ed., Contemporary Irish Migration (Dublin: Geographical Society of Ireland Special Publication no. 6, 1991), 55-69. 
tory pattern between Great Britain and Ireland during the 1950s. ${ }^{7}$ Highly qualified emigrants, whose movement abroad was prompted primarily by career considerations, returned to Ireland in significant numbers in the I950s. O'Brien suggests that this decade marked an important (and thus far overlooked) quantitative and qualitative transition between earlier types of outflows and contemporary migratory trends.

A second study is that of Gmelch, who examined the experiences of return migrants in the 1970 , focusing on return migration to eight western counties-Cork, Kerry, Clare, Galway, Mayo, Sligo, Leitrim, and Donegal-all located on the predominantly rural and relatively impoverished western seaboard. ${ }^{8}$ Gmelch questioned his sample of over six hundred returned emigrants on a range of issues, including their circumstances before emigration, the emigration experience, their reasons for return, and post-return adjustment. He found that the majority experienced problems with readjusting to Ireland, although only 20 percent still regretted their decision to return at the end of the second year. The problems of readjustment especially in the first year home were attributed to the false or unrealistic expectations returners had about life in Ireland. Respondents cited the slow pace of life and widespread inefficiency as their biggest problems on return. The perceived backwardness of the local population and the difficulty in establishing relationships also impeded successful readjustment. An overwhelming majority ( 85 percent) felt that they had been changed by the experience of emigration. More than two-thirds felt that they had a broader outlook than those who had never left Ireland.

A study conducted by McGrath some ten years later echoed these findings. ${ }^{9}$ McGrath conducted one hundred forty-two interviews with returned emigrants on Achill Island, off County Mayo, in 1988. Among the primary readjustment problems for this cohort were the poor economic situation, the attitudes and gossip of locals, inefficiency, and the slow pace of life. McGrath also found corroborating evidence to support O'Malley's claim that returned emigmnts tended to find fault with every-

7 Matthew O'Brien, "Migratory Patterns of the I9sos Generation." Paper presented at the international conference on "The Scattering," University College, Cork, September 1997.

8 G. Gmelch, "The Readjustment of Returned Migrants in the West of Ireland," in R. King, ed., Retum Migration and Regional Economic Problems (London: Croom Helm, 1986), 152-70.

9 McGrath, "The Economic, Social and Cultural Impact of Return Migration to Achill Island."

THE EXPERIENCES OF RETURNING IRISH EMIGRANTS 
thing in Ireland, thereby creating an unnecessary mental barrier between themselves and the home setting. ${ }^{10}$

According to Barrett and Trace, the current cohort of returning emigrants have higher levels of educational attainment than the resident population. ${ }^{11}$ Furthermore, there appears to be a selection process whereby the returners are those with the higher levels of education among the group who left. The current population of returners, therefore, can be broadly described as a highly educated group that has amassed considerable cultural capital and career experience during their sojourns abroad. Statistics alone, however, cannot provide insight into the motivations, decision-making, and experiences of those who left Ireland and have now returned. Rather than viewing migrants' experiences purely "in behavioural terms as manifest responses to particular configurations of opportunity and constraint," I am interested in the deeper question of how emigrants make sense of their lives. ${ }^{12}$ For that kind of information we need more qualitative techniques for data collection and analysis.

\section{THE METHODOLOGY}

My aim at the outset of the current study was simply to illuminate the experiences of returned emigrants who feature in statistical calculations but not elsewhere. Yet the statistical elusiveness of this group demands more informal techniques. My training as a sociologist has been very much in the tradition of qualitative research methodology, in which the research participant is enabled "to define the situation." During the second half of the r980s I researched the Irish immigrant community in New York City, making and sustaining relationships with a wide cross-section of Irish emigrants. ${ }^{13}$ Drawing on these social networks, along with familial and work networks in Dublin, I have generated a population frame of returners. In addition, I was able to contact returning emigrants through an advertisement placed in the newsletter of the High Skills Pool distributed

Io E. O'Malley, Memories of a Mayoman (Dublin: Foilseachán Naisiúnta Teoranta, 198r).

II Alan Barrett and Fergal Trace, "Who is Coming Back? The Educational Profile of Returning Migrants in the I990s." Paper presented to the Irish Economic Association, University College, Dublin, 23 June 1998.

12 Roger Rouse, "Making Sense of Settlement: Class Transformation, Cultural Struggle and Transnationalism among Mexican Migrants in the United States," Annals of the New York Academy of Science 645 (1992), 26. I am indebted to Professor Eithne Luibheid for introducing me to the work of Roger Rouse.

13 Mary P. Corcoran, Irish Illegals: Transients Between Trwo Societies (Westport, Conn.: Greenwood Press, 1993). 
to prospective and recently returned emigrants. ${ }^{14}$ To broaden the population I have asked each returned emigrant interviewed to refer me to another who is unknown to me. This is a form of "snowball sampling" often used when particular populations are difficult to access in a random way.

Between July 1997 and March 1998 I conducted twenty-three in-depth interviews with returners. My stipulation was that the emigrant must have left Ireland in the 1980s and returned in the 1990s. The majority of those interviewed either had advanced educational qualifications before leaving Ireland or had completed advanced-mainly postgraduate-qualifications on their return. So, strictly speaking, my population falls into the relatively privileged category of "credentialized" emigrants. However, a study of the educational level in 1992 of a sample of young people who left school in 1986, carried out by the Dublin-based Economic and Social Research Institute, suggests that my sample is not unrepresentative. This study showed that only 5 to 6 percent of those young people who left school without a qualification were abroad, is percent of those with a Junior or Leaving Certificate were outside the country, while about 25 percent of those with a higher education qualification had emigrated. ${ }^{15}$ Furthermore, Barrett and Trace's analysis confirms that returners have a relatively high level of educational attainment compared to that of the general population. ${ }^{16}$

Interviews with respondents lasted approximately ninety minutes and covered a range of issues including motivation for leaving, decision-making processes, goal attainment, self-identification and ethnic identification, perceptions about Ireland, adjustment problems, and so on. Interviews were conducted in the interviewee's home, my home, or a neutral public venue such as a café or bar. All of the interviews were tape-recorded and transcribed. In this paper, I focus on a number of themes that emerged from analyzing the data. These themes suggest that a key aspect of the migratory experience for returners was the opportunity afforded them to reflexively "reinvent the self." This opportunity, of course, is predicated on the confluence of a number of different factors, including

I4 The High Skills Pool is an agency funded by FAS (the State Training Agency). The agency maintains a database and channels information on industry and business opportunities in Ireland to graduates overseas. It publishes a quarterly magazine, Inform, which is sent to more than 5,500 graduates abroad.

I5 Garret Fitzgerald, "Population Implications in our Balanced Migration," Irish Times, I February 1997.

16 Barrett and Trace, "Who is Coming Back?" 
high levels of cultural capital on the part of the emigrant, the presence of a risk-taking/entrepreneurial culture, and more flexible labor markets. The ability to make meaningful choices in relation to one's life-plan is characteristic of a particular type of Irish emigrant at a particular historical point in time.

The process of reinvention tended to occur in three stages: a growing sense of self-awareness and the need for self-actualization; a review of existing goals, the setting of new goals, and goal attainment; and the reconfiguration of the self, based on newly acquired skills and experiences. ${ }^{17}$ The following section details the experience of returning emigrants in terms of these three themes.

\section{SELF-AWARENESS AND SELF-ACTUALIZATION AT THE PROFESSIONAL AND PERSONAL LEVELS}

All of the returners interviewed were highly self-aware. Prior to the interview, most had reflected at length on the kinds of issues I wanted to raise. Indeed, all of the respondents had engaged in self-conscious monitoring of the self on an ongoing basis, a trait identified by Beck and Giddens as being quintessentially part of the modern individualization process. ${ }^{18}$ This meant developing a perspective or explanation as to why they had left Ireland, reflecting on what the experience of emigration had actually meant to them, and rationalizing the decision to return home. In choosing to go abroad, most of the interviewees were responding to a need to self-actualize, that is, to fulfill their potential in ways not possible at home, because of a variety of structural and social constraints. For example, Kieran earned a degree in electrical engineering and moved to London in 1988.19 There he worked for a London financial institution in banking software, before moving to a British university to complete a Ph.D. He returned to Ireland in 1997 and took up a position as a lecturer at an Institute of Technology:

17 Once embarked on the emigration trail these emigrants attempted to sustain "coherent, yet continuously revised biographical narratives ... in the context of multiple choice as filtered through abstract systems," to quote Anthony Giddens, Modernity and Self Identity (Cambridge: Polity Press, 1991), 6. The absence of structural constraint (in the form of low educational attainment, familial expectation and obligation, peer pressure, labor market inflexibility) freed them from the tyranny of a linear career path.

I8 See, for example, Ulrich Beck, Risk Society: Toward a Nerw Modernity (London: Sage, 1992) and Giddens, Modernity and Self Identity.

ig All names of interviewees have been changed to ensure anonymity.

THE EXPERIENCES OF RETURNING IRISH EMIGRANTS 
At first I was going to work for a couple of years in banking and then go travelling, but then I decided to start saving so that I could do a postgraduate degree. I guess what triggered that was that I was getting a bit cheesed off with work. Work was good in that conditions of service were good, good pay, foreign travel, and good benefits. But on the downside the work was very boring. Well, writing banking software wouldn't be the most productive job in terms of doing anything useful apart from making fat-cat bankers fatter, do you know what I mean? It was like, do I really want to do this? I could see the future, and the future was backache, ulcer and goK a year if you wanted. I could see people at that stage-doing well financially but quite bored. I thought in academia there would be more opportunities. The financial rewards wouldn't be as good but it is a bit more satisfying. ${ }^{20}$

Similarly, Peter, a science graduate, spent almost a decade in London doing a variety of short-term contractual work related to the arts-based courses he took while living there. He eventually returned to Dublin and opened his own art gallery:

The context of my initial decision to go away was that I had finished a degree in Science which I realized I wasn't going to use. I wasn't going to seek employment related to my degree. I was twenty-two years and heading off casually rather than to take up a post university post. It was easier to go to London ... it had the bright lights, big city attraction. By the end of my second year there I was living on the dole and taking all sorts of courses in areas that had been denied to me educationally in Dublin. Typically, like a lot of Irish people I was told by the Christian Brothers at the age of thirteen, that sorry, you are too intelligent not to do Latin, Science, whatever. So in London I actually did classes on anything from tailoring and pattern cutting to jewelry making to set and costume design and explored that whole area that I hadn't explored before. It opened up a whole other part of myself. ${ }^{21}$

Maeve graduated with a degree in economics at the end of the 1980 and immediately went to the United States. During her five-year sojourn, she spent several years working as a waitress before going to work for a law firm. On her return to Ireland she went back to do a postgraduate degree in community work and now works in that field. She, too, was philosophical about her time spent abroad and what she hoped to gain from the experience:

20 Interview with returner, Dublin, 15 January 1998.

21. Interview with returner, Dublin, I7 July 1997. 
My quality of life was good in terms of the freedom, in the explorative sense, and the broadening of the mind. Being in college was like being in the Bastille really, it was narrow, limited, and you didn't meet a very wide variety of people. I felt I had to get to know other sides, other people, other ways of looking at things.and I achieved that: ${ }^{22}$

This sense of going abroad to work as primarily a "broadening experience" was reiterated by Patrick, another engineering student, who completed his program in 1987 and subsequently worked in London in the financial services sector: "I suppose the good thing about London is that it is a real melting pot so that you get to see a bit of everything. If you want.it to be, it will be a mind-broadening experience. ${ }^{23}$ Both in professional and personal terms, then, respondents saw the experience of migration as an opportunity for self-actualization. Although leaving home and family for the unknown involved some element of risk-taking, this was more than compensated for by the chance to grasp new opportunities, make lateral rather than linear career moves, and explore hitherto unexplored parts of the self.

\section{GOAL-SETTING AND GOAL ATTAINMENT}

Most of the returners did develop goals over the period spent abroad but, crucially, these goals were formed in the context of a perception of multiple choices, and the availability of alternative opportunity structures. This capacity to generate a personal biographical narrative free of constraints was perceived as a form of empowerment.

Patrick, who trained as an engineer, became increasingly disillusioned with the lifestyle that went with his job in the financial services sector in London. Although he was earning a relatively high salary, he found the job extremely stressful. After reviewing his position he opted to move into the wine trade. On his return to Ireland in 1997 he took a position as a wine store manager, the equivalent of an entry-level position in his chosen trade:

At some point along the way I asked myself what do I want to do with my life ... I had to set myself some goals. I had been drifting through jobs in banking services. It was very tedious. I ended up working in a big American bank as a foreign exchange dealer for four years. It was an interesting time, and an exciting trade, fast, furious and dramatic. It was very well paid so my standard of living dramatically increased. But also there was a hor-

22 Interview with returner, Maynooth, I7 September 1997.

23 Interview with returner, Dublin, 27 August 1997. 
rible side to it ... you worked with a lot of obnoxious, greedy people who held extremely right wing views. I decided, let's knock this on the head and try to get into something different. So I went into the wine trade starting at the bottom. I became more focused, I decided where I wanted to go, and I made some tough decisions. ${ }^{24}$

Rebecca's goals also evolved while she was abroad, although in her case there was a stronger focus on personal rather than strictly professional development (even if the two are often closely related). Rebecca trained as a social worker and spent several years working in that profession in a remote part of Canada. She later took time out from her profession to work as a cook on a boat. Since returning to Ireland in 1995, she has been working as a social worker and pursuing postgraduate studies:

When I say that I didn't have goals, I mean that I didn't have professional goals when I went out [to Canada] but I had more personal goals which were to travel, to be able to experience Canada and the Canadian way of life. I didn't want to earn a lot of money and I didn't see it as a career move ....My goal was to do something different than what I had qualified in [social work] and when I went on to do that, I did it in a way that was enviable to others. I ended up taking something that was a hobby and skill and being able to use that as a goal, to expand that and become really good at that so that I would have another career option open to me..$^{25}$

Similarly, Rita, who had also trained as a social worker, recognized the developmental potential of working in another country. In particular, she commented on the positive perspective she developed about her work because of the affirmative work culture she experienced. Since returning to Ireland, she continues to practice as a social worker although she feels somewhat disillusioned about the nature of social work practice in Ireland as compared to Canada:

Work was a very different experience in Canada than it had been in Ireland. I think there was a more professional attitude toward social work. People that I mixed with professionally were very goal-oriented. It's prompted by things like going for an interview and being asked what are your goals for the next five years ... and you have never thought of them before in your life.... What do you say, my career goal is to get out of bed in the morning! I had never thought in that way before, but I did develop that mentality. Within a year of being there I decided that I wanted to get more train-

24 Interview with returner, Dublin, 27 August 1997.

25 Interview with returner, Wexford, is July 1997. 
ing.... I started on a sort of "training train." And I never got off it in a way. I did start to see myself as a professional and view myself as someone who had a career in a way that I hadn't done previously in Ireland. ${ }^{26}$

Self-monitoring involves a constant evaluation of the individual's life plan and goals. In the case of these returners, goal-setting and goal attainment became important benchmarks in their career trajectory, whether those goals were set personally or professionally. Furthermore, over a period of years a career path crystalized, with many graduates ending up in jobs unrelated to the discipline in which they trained. Nevertheless, there was considerable agreement among the interviewees that their general education had been a useful indirect, if not direct, resource in developing a career path.

\section{THE REINVENTION OF SELF}

All of the interviewees agreed that their lives had been enriched by the experience of emigration. They felt that they had added to their cultural capital particularly in terms of their abilities to take risks and to make choices, and in terms of the development of self-confidence and self-assurance. These qualities, they felt, made them different in a positive way from their peers who had stayed at home.

For example, Jean left school after her Intermediate Certificate and moved to London. There she worked her way up to become a senior sales executive in a British company. In 1996, after her first child was born, she and her husband returned to Ireland for quality-of-life reasons. Jean moved back to her home place where most of her family still live, and she perceives a qualitative difference between herself and her siblings who never left home:

I am much more broad-minded [than my sisters who stayed here]. They would still have the old Irish way ... they feel they are not good enough, and they'll never get that job, blah blah. And they are really negative about everything. Whereas I am really positive about everything, and if I applied for a job and I didn't get it, yes I would be disappointed but I would ring the person up and ask why I didn't get the job. Not because I was having a go at them but so I could find out where I went down at the interview so it won't happen again. I wouldn't have had the courage to do that when I was living in Ireland; I mean I just believe in myself now. What London has done for me is to make me realize that as a person I am valu-

26 Interview with returner, Wexford, I7 October 1997. 
able to somebody else in every sense of the word, relationships, work, friends, everything. It has made me a positive person. . . .27

Rita, the social worker, also commented on how living abroad strengthened her self-esteem:

I have developed a more "can-do" attitude, and I am much more goal-oriented. I have a greater degree of self-assurance about myself. That is to do with the fact that I am older, but also because of my Canadian experience of self-assurance $\ldots$ being with people who were goal-directed, who were more self-assured, like being in a society where you ask people what are they good at, and they give you a list of things. Whereas in Ireland you would say not very much, really. That has to have an impact on you. ${ }^{28}$

These returners embody many of the characteristics ascribed to the individual by recent theorists. The current social formation is characterized by a collapsing of the constraints of time and space, and a concomitant interpenetration of the global and local. There is increased concentration and centralization, particularly at the institutional level, and increased fragmentation and de-traditionalization at the individual level. Individuals are increasingly being forced to negotiate lifestyle choices, or ways of living, among a diversity of options. ${ }^{29}$ The history of Ireland in the modern era has been one of the incorporation of its workers into an international division of labor, such that Irish emigrants have contributed to the secondary labor market and the informal economies of a number of host countries. A more recent trend is the incorporation of a new type of Irish emigrant-the transnationally mobile educated élite-into primary sector positions in "global" cities.

Lash and Urry, among others, argue that in the context of the new transnational economy there is greater potential for individuals to act as reflexive agents, to take control, in a sense, of the shaping of their own lives. "The modernisation and postmodernisation of contemporary political economies," they argue, "produce, not just a flattening, but a deepening of the self." "31 Mass education, the growth of information technology, the

27 Interview with returner, Dublin, 27 August 1997.

28 Interview with returner, Wexford, 17 October 1997.

29 Giddens, Modernity and Self Identity, 9.

30 See Gerard Hanlon, The Commercialisation of Accosntancy (London: St. Martin's Press, 1994).

3I Scott Lash and John Urry, Economies of Signs and Space (London: Sage, 1994), 31. My emphasis. 
rapid expansion of the specialist service sectors, and more flexible labor markets generate new opportunities for the individual, offering greater opportunity "to reflect critically on those changes, and on their social conditions of existence, and potentially to change them." ${ }^{32}$ Giddens' conceptualization of the "reflexive individual" is also infused with a sense of agency; we are not simply what we are, but what we make of ourselves. ${ }^{33}$

This concept of the "reflexive self" goes some way toward helping us to make sense of those individuals who, having emigrated from Ireland in the 1980 s, chose to return in the I99os. In their emphasis on self-awareness and self-actualization, their explicit reworking of their goals, and their desire to gain more control over their biographical narratives, they demonstrate the triumph of agency over structural constraint. The decision to emigrate and then to return seems to presage a period of "reflexive individualization" in which individuals have been empowered to invent and reinvent their personal biographical narratives. They have forged "flexible subjectivities" in the context of a transnational field of action, developing, in the words of Roger Rouse, "the capacity for rapid and dramatic processes of self-transformation, for synthesizing and recombining disparate elements and forms of personhood, and above all, for moving fluidly back and forth between markedly different modes of experience and arenas of activity." 34

However, the interplay between culture, class, and power is critically important in understanding the panoply of Irish emigrant experiences in the transnational economy. As Rouse points out, "people destined for professional managerial activities have been equipped with attitudes to time and space, persona and sociality significantly different from people directed toward wage work." 35 Hence, any model of migration must account for class differences and concomitant differentials in cultural capital between different categories of emigrants.

The model in Table 2 is an attempt to encapsulate the impact of these differences. The élite are well positioned to make reflexive decisions about their careers, driven by the desire to self-actualize. They tend to be highly individualistic and enjoy a considerable degree of personal agency in terms of their life plans and career choices. In contrast, the more tradi-

32 Ibid., 37.

33 Giddens, Modernity and Self Identity, I96.

34 Roger Rouse, "Thinking about Transnationalism: Notes on the Cultural Politics of Class.Relations in the Contemporary United States," Public Culture 7 (I995), 391.

35 Rouse, "Making Sense of Settlement," 26. 
tional Irish emigrants, whose role was to fill the gaps in the secondary labor market of global cities, are much more constrained. Their decisionmaking is frequently contingent and inadequately thought-through. They gravitate very much toward their ethnic group, where informal networks facilitate their entry into the labor market. ${ }^{36}$ They may be subject to a variety of constraints ranging from prejudice and discrimination to the vagaries of the host country system of immigrant regulation.

TABLE 2

\begin{tabular}{lll}
\hline Process of migration & $\begin{array}{l}\text { "Reserve army } \\
\text { emigrants" }\end{array}$ & Professional élite \\
\hline Decision-making & Contingent & Reflexive \\
Migratory context & Ethnicization & Self-actualization \\
Migrant persona & Situational ethnicity & Flexible subjectivity \\
Migratory experience & Structural constraint & Personal agency \\
\hline
\end{tabular}

What I am suggesting here is a clear demarcation between two types of emigrants who left Ireland in the 1980s: on the one hand, the "reserve army emigrants," who represent a surplus in the context of the Irish labor market and who consequently sought work elsewhere, and, on the other hand, a professional élite who are empowered to choose whether or not to stay in Ireland and whether or not to follow a linear career path. The former group make decisions that are primarily determined by the prevailing economic conditions. Furthermore, they are likely to be constrained in terms of opportunity structures because of low or non-transferable skills. The latter group makes decisions that tend to be reflexive, that is, based on an ongoing and self-conscious evaluation of personal and professional goals. The context of reception in the host country is different for each group. The "reserve army emigrants" tend to be absorbed quickly into the Irish ethnic niches in the labor market. Furthermore, they tend to live in the same neighborhoods and congregate in the same bars and cafés. In contrast, the professional élite tend to reject both symbolic and substantive ethnicity, preferring to make their way as individuals without unduly advertising their Irishness, particularly in the workplace. While the "reserve army emigrants" find that to survive in the host country they must often develop an ethnic persona in a variety of strate-

36 See Corcoran, Irish Illegals.

THE EXPERIENCES OF RETURNING IRISH EMIGRANTS 
gic situations, the professional élite are busy deploying their flexible subjectivities across a range of work and leisure arenas. Finally, it seems clear that the experiences of "reserve army emigrants" most closely mirror those of previous generations of Irish emigrants, bounded as they are by structural constraint in the form of economic and social conditions as well as legal barriers. Members of the Irish professional élite, in contrast, embody many of the attributes associated with modern individualization. Rich in cultural capital and attuned to information and communication structures, they apply themselves assiduously to the task of self-fulfillment. For many, this results in a reflexive reinvention of the self.

\section{THE CONSTRAINTS ON REFLEXIVITY}

For returners, a key choice that has been made is to return home. Why are these emigrants coming home? The answer lies at least in part in a quest for anchorage, for attachment to others and a sense of continuity. Often these corrections can be found in the ethnic communities that flourish in global cities. But for those among the professional élite of Irish emigrants who neither seek nor engage with the ethnic community, the quest for anchorage remains unfulfilled. The process of individualization at the heart of modern capitalist development confers on them a sense of agency. This is apparent particularly in relation to their work lives. All of the interviewees felt that the training and experience obtained abroad had contributed to their cultural capital. Most had reached points in their careers where they were in a good position to make informed choices about their next move. At the same time, the cult of individualism, whose logical extension is the application of market values across non-economic spheres of life, creates a kind of "existential isolation"-what Giddens defines as "not so much a separation of individuals from others as a separation from the moral resources necessary to live a full and satisfactory existence." 37 Put another way, "there is an increasingly felt need for some expressive relationship to the past and for attacbment to particular territorial locations as nodes of association and continuity, bounding cultures and communities." 38 For the returners, this need is expressed in the desire to return home:

37 Anthony Giddens, Modernity and SelfIdentity, 9.

38 M. Rustin, "Place and Time in Socialist Theory," Radical Philosopby 47 (Autumn r987), 33-34, qtd. in David Morley and Kevin Robins, "No Place Like Heimat: Images of Home(land) in European Culture," in E. Carter, et al., eds., Space and Place (London: Lawrence and Wishart, 1993), 3-3r. My emphasis. 
It sounds corny but I just decided, this is where I belong, this is where I fit in. It just became very obvious to me, this is where I feel relaxed, this is where I feel at home. This is the social place where I seem to be myself. ${ }^{39}$

Or:

There was always something that I felt was missing. I suppose you call it homesickness, but maybe it was more about me and where I was at. . . I don't think its something that can be easily articulated. ${ }^{40}$

Not surprisingly, the central considerations in the decision to return to Ireland include the provision of a better quality of life for children, having more time, the ease of Irish sociability, the quality of friendship, and the slower pace of life. Paradoxically, the very pace of life that had caused the most serious adjustment problems for the returned emigrants interviewed by Gmelch and McGrath in the 1970 and 1980 s is eulogized by those who returned in the I99os. Today's returners want to feel part of something that one might describe as an organic, as opposed to a synthetic, community. There is a sense in which they want to commune with their own, with friends and family to whom they have longstanding feelings of attachment. This contrasts with their existence in global cities, which-while free of much constraint and highly flexible-was characterized by a compartmentalized lifestyle whereby the individual remained detached from groups and institutions.

Ironically, the rise of the "Celtic Tiger" economy has facilitated the return of emigrants in significant numbers but is also inextricably bound up with growing individualism. Ireland itself has been incorporated into the globalizing project of multinational capital. The private sector, in particular, now demands the same level of commitment from Irish-based employees as the parent company and its international counterparts. This puts at risk the kind of lifestyle that the returning emigrants covet. They have difficulty in acquiring reasonably priced housing, commuting times are considerably longer and more frustrating than they had anticipated, and there is less time than they had hoped for to enjoy a social life:

Whether you are working in NY, Paris, London, or Dublin-whether it is for Rank Xerox, Jackson Stopps, or my company-people are expected to have the same work rate. A friend of mine worked for an accountancy firm taken over by a Big Six company, he worked in the UK for a while, then

39 Interview with returner, Dublin, 27 August 1997.

40 Interview with returner, Maynooth, I8 September 1997. 
in Belgium and now in France, and really he is mobile within a firm rather than mobile across countries. He is just an autonomous economic unit that can be slotted in anywhere, and they expect his work rate to be the same, to hell with the social externalities. You are a little unit for us go produce the standard amount of output a day. That's very unhealthy. Because it homogenizes. We are homogenizing culturally, but we are also homogenizing economically. ... I thought it would be different when I returned. I thought for me personally and psychologically I would get up and approach work differently, that my attitude would change. That I wouldn't be a harassed urban dweller anymore. That I would be relaxed, a less stressed individual. But because of the nature of the job, the company I am working for, and the fact that Dublin has changed that's not happening. ${ }^{41}$

The concept of a "positional economy" is relevant here. Fred Hirsch defines the positional sector of the economy as all aspects of goods, services, work positions, and other social relationships that are scarce in some absolute or socially imposed sense, and subject to congestion or crowding through more extensive use. The choices facing the individual in a market-type transaction in an expanding positional sector, for Hirsch, always appear more attractive than they turn out to be after others have exercised their choice..$^{42}$ In other words, the satisfaction that returning Irish emigrants may derive from goods and services depends increasingly not only on their own consumption but on others' consumption as well. In a booming economy characterized by net immigration rather than net emigration, where the demands of an expanding middle class are outstripping supply, the acquisition of positional goods becomes ever more difficult. The returning emigrants find themselves caught in a bind. Ireland's exemplary economic performance makes the dream of return possible, but that economic performance is based on the very values and practices from which these returning emigrants are attempting to escape.

4 Interview with returner, Dublin, II October 1997.

42 Fred Hirsch, Social Limits to Growth: New York: Twentieth Century Foundation (Cambridge, Mass.: Harvard University Press, $x_{976}$ ). 


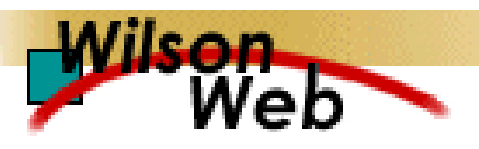

\section{COPYRIGHT INFORMATION}

TITLE: The Process of Migration and the Reinvention of Self: the Experiences of Returning Irish Emigrants

SOURCE: Eire-Ireland 37 no1/2 Spr/Summ 2002

WN: 0210504970013

The magazine publisher is the copyright holder of this article and it is reproduced with permission. Further reproduction of this article in violation of the copyright is prohibited. To contact the publisher: http://www.irishaci.org/.

Copyright 1982-2002 The H.W. Wilson Company. All rights reserved. 